\title{
Impact of COVID-19 crisis on medical care of patients with metastasized uro-oncologic disease under systemic cancer therapy: a multicenter study in German university hospitals
}

\author{
Julian P. Struck ${ }^{1}$ (1) Maike Schnoor ${ }^{2} \cdot$ Andrea Schulze $^{1} \cdot$ Marie C. Hupe $^{1} \cdot$ Tomasz Ozimek $^{1} \cdot$ Immanuel A. Oppolzer $^{3}$. \\ Marco J. Schnabel ${ }^{3}$. Maximilian Burger ${ }^{3}$. Christopher Darr ${ }^{4}$. Viktor Gruenwald ${ }^{4}$. Boris Hadaschik ${ }^{4}$. \\ Maximilian Weinke ${ }^{5} \cdot$ Hubert Kuebler $^{5}$. Jonas C. Klockenbusch ${ }^{6}$. Markus T. Grabbert ${ }^{6} \cdot$ Christian Gratzke $^{6}$. \\ Mario W. Kramer ${ }^{1} \cdot$ Alexander Katalinic $^{2} \cdot$ Axel S. Merseburger $^{1}$
}

Received: 20 July 2021 / Accepted: 20 October 2021 / Published online: 30 November 2021

(C) The Author(s) 2021

\begin{abstract}
Purpose To date, over 4.2 million Germans and over 235 million people worldwide have been infected with severe acute respiratory syndrome coronavirus 2 (SARS-CoV-2). Uro-oncology (UO) patients are particularly vulnerable but in urgent need of life-saving systemic treatments. Our multicentric study examined the impact of the COVID-19 crisis on the medical care of UO patients in German university hospitals receiving ongoing systemic anti-cancer treatment and to detect the delay of medical care, defined as deferred medical treatment or deviation of the pre-defined follow-up assessment.

Methods Data of 162 UO patients with metastatic disease undergoing systemic cancer treatment at five university hospitals in Germany were included in our analyses. The focus of interest was any delay or change in treatment between February 2020 and May 2020 (first wave of the COVID-19 crisis in Germany). Statistical analysis of contingency tables were performed using Pearson's chi-squared and Fisher's exact tests, respectively. Effect size was determined using Cramér's V (V).

Results Twenty-four of the 162 patients (14.8\%) experienced a delay in systemic treatment of more than 2 weeks. Most of these received immuno-oncologic (IO) treatments $(13 / 24,54.2 \%, p=0.746)$. Blood tests were delayed or canceled significantly more often in IO patients but with a small effect size $(21.1 \%, p=0.042, V=0.230)$. Treatment of patients with renal cell carcinoma $(12 / 73,16.4 \%)$ and urothelial carcinoma $(7 / 32,21.9 \%)$ was affected the most.

Conclusions Our data show that the COVID-19 pandemic impacted the medical care of UO patients, but deferment remained modest. There was a tendency towards delays in IO and ADT treatments in particular.
\end{abstract}

Keywords Uro-oncology · COVID19 · COVID-19 $\cdot$ SARS-CoV-2 · Pandemic $\cdot$ Medical care

\section{Introduction}

To date, over 4.2 million people in Germany, over 71 million in Europe and over 235 million people worldwide have been infected with the betacoronavirus known as severe acute respiratory syndrome coronavirus 2 (SARS-CoV-2). The worldwide death toll of the lung disease COVID-19 caused by the virus is up to 4.8 million [1] and it is still rising. With almost 94,000 confirmed deaths and a case fatality ratio of $2.2 \%$ [2], Germany seems to be less affected by the

Julian P. Struck

julian.struck@uksh.de

Extended author information available on the last page of the article crisis than many other countries around Europe like France (over 7 million cases, over 117,000 deaths) or the United Kingdom (over 8 million cases, over 137,000 deaths) and around the globe [2]. Still, it changed daily life of medical professionals and other groups in Germany and around Europe, including several lockdowns of amusement places, swimming pools, churches, restaurants, schools, universities and other meeting places to avoid a spread of infection, severe hygienic measures being taken, and led to numerous overloads of hospital capacity [3].

As in many other disciplines, urooncologic research and care in Germany [4] as well as urologic training, research and care around the globe [5-7] have been affected by the COVID-19 crisis. Planned operations had to be delayed [8], video consultations were introduced [3], special hygienic 
preparations were taken [3] and the inclusion of potentially vulnerable patients in clinical studies had to be delayed [5, 6]. Recently, our working group reported severe adverse disease outcomes and a decrease in emergency room visits for patients with pyelonephritis in the COVID-19 era [9]. Special care must be taken of our elder, chronically ill, multimorbid patients and people in need of special care as they seem to be particularly susceptible to COVID-19 infections $[10,11]$. This applies also to uro-oncology (UO) patientsnot only do they bear a higher risk for more severe COVID19 infection courses, they also suffer directly from an overload of the health system [12]. These patients, especially with metastatic disease, often do not only need systemic cancer therapies that cannot be delayed or which are connected to repetitive outpatient and inpatient hospital care. Their underlying uro-oncologic diseases (urothelial/renal/ prostate/testicular/penile cancer) or systemic, immuno-modulating therapies also lead to immunosuppression of long duration to some extent. This risk population is confronted with progression risks caused by delayed therapy on the one hand and the risk of severe COVID-19 infections and higher mortality rates on the other $[10,11]$.

\section{Theory}

There is still a knowledge gap concerning the impact of the COVID-19 pandemic on this specific patient group in Germany, especially in German university hospitals which often maintain medical care in times of crisis such as the COVID-19 pandemic while other hospitals might reach their supply limits. So far, German data concerning oncologic care during COVID-19 crisis have been mostly raised via web-based surveys $[4,13]$ or have been provided by German health insurances [14]. Our evaluation of the effects of the COVID-19 pandemic on the medical care of patients with metastasized uro-oncologic disease under systemic cancer therapy in German university hospitals should help to identify the potential undertreatment of this patient cohort. In particular, we tried to answer the following questions:

How does the COVID-19 pandemic change or influence the care of UO patients in university hospitals under ongoing systemic treatment? Is there a significant difference between urologic cancer entities or substance groups? Do delays in systemic treatment due to the COVID-19 crisis have an impact on the prognosis and survival of these patients?

\section{Patients and methods}

Between the beginning of the first COVID-19 wave that struck Germany at the end of January 2020 and the end of this wave in June 2020, a total of 162 UO patients with metastatic disease and at least 18 years of age who received systemic anti-cancer treatment at the university hospitals of Luebeck, Regensburg, Freiburg im Breisgau, Wuerzburg and Essen were included. Data were retrieved from medical records. The treatments were delivered as routine medical care. The patients did not receive any additional therapies, medication or imaging for the purpose of this study. Anti-cancer treatment with chemotherapy and immuno-oncologic (IO) treatments including checkpoint inhibitors (CPI) or androgen deprivation therapies (ADT) were permitted. It was mandatory for the last radiologic restaging to be dated before the beginning of the COVID-19 pandemic in February 2020 to ensure the baseline oncological status before the pandemic. The key clinical and diagnostic parameters assessed were: age, sex, patient's performance status by measuring patient's level of functioning in terms of their ability to care for themselves, daily activity, and physical ability using the Eastern Cooperative Oncology Group (ECOG) classification, comorbidities, immunosuppressing treatments, tumor stage and entity, systemic anti-cancer therapy, previous radiation and surgical therapies, SARS-CoV-2 and influenza status, medical care including delays in therapy or restaging of more than 2 weeks. Institutional Review Board (IRB) approval was obtained from the Ethics Committee of the University of Luebeck (no. 20-156). The patient data were evaluated retrospectively and subsequently anonymized from the data source onwards. No additional written consent was required. The primary aim was to detect the delay of medical care, defined as deferred medical treatment or deviation of the follow-up assessment. Delays were measured as deviations from the standard times for uro-oncological therapies, follow-up imaging and follow-up examinations, as listed in the approval studies for the respective substance and in the German and European urological guidelines of the German (DGU) and European (EAU) societies for urology.

As a secondary aim, we tested whether tumor entity or treatment modality was associated. Statistical analysis of contingency tables was performed using Pearson's chisquared and Fisher's exact tests, respectively. Effect size was determined by calculating Cramér's $V(\mathrm{~V})$ [15] to evaluate the association between tumor entity or treatment modality and delay in follow-up and treatment, respectively. Effect size was defined as small for $V=0.1$, medium for $V=0.3$, and large for $V=0.5$ [16]. The significance level was set to $\alpha=0.05$. SPSS v22.0 was used (IBM Corp., Armonk, NY, USA) for all analyses and data management.

\section{Results}

All reported changes regarding aftercare and therapy fell during the period of the first Covid wave and the first Covid-related lockdown in Germany from February 2020 to June 2020 . The majority of patients were male (87.6\%); 
median age at the time of inclusion was 68.5 years (range 33-89 years); $81.9 \%$ of cases exhibited favorable clinical conditions (ECOG performance status 0-1). More detailed patient characteristics are presented in Table 1. Only 1/49 SARS-CoV-2 PCR tests conducted were reported positive. The patient did receive in-house care because of the SARSCOV-2 infection but without intensive care and he recovered fully.

Our data revealed that $30 / 161$ patients (18.6\%) experienced a therapeutic change due to the COVID-19 pandemic
(Tables 2 and 3). Of those, 24 (80\%) experienced a delay in the systemic treatment of more than 2 weeks; three patients (10\%) had a switch in their therapeutic agents. Most of the patients who experienced a delay in systematic treatment received IO treatments $(13 / 24,54.2 \%)$ or ADT $(5 / 24,20.8 \%$, $p=0.746$, Fig. 1). In only one case was treatment completely interrupted. 53 (32.3\%) patients experienced a change in their follow-up and imaging schedule (Tables 4 and 5). In 17 (32.1\%) of these 53 cases, radiologic follow-up had been delayed; in five cases (9.4\%) it was cancelled. In 16/53

Table 1 Patient characteristics

\begin{tabular}{|c|c|c|c|c|}
\hline Characteristics & $\begin{array}{l}\text { No change in therapy or } \\
\text { follow-up }\end{array}$ & $\begin{array}{l}\text { Any change in therapy or } \\
\text { follow-up }\end{array}$ & Total & $p$-value* \\
\hline \multicolumn{5}{|l|}{ Sex (1 missing value) } \\
\hline Male & $93(66.0 \%)$ & $48(34.0 \%)$ & 141 & \multirow[t]{2}{*}{0.025} \\
\hline Female & $8(40.0 \%)$ & $12(60.0 \%)$ & 20 & \\
\hline Age (median, range) & $67(33-88)$ & $67.5(48-89)$ & $67.1(33-89)$ & 0.202 \\
\hline \multicolumn{5}{|l|}{ Diagnosis } \\
\hline Castration-resistant prostate cancer & $22(66.7 \%)$ & $11(33.3 \%)$ & 33 & \multirow[t]{8}{*}{0.304} \\
\hline Hormone-sensitive prostate cancer & $11(64.7 \%)$ & $6(35.3 \%)$ & 17 & \\
\hline Renal cell carcinoma & $41(56.2 \%)$ & $32(43.8 \%)$ & 73 & \\
\hline UTUC & $7(77.8 \%)$ & $2(22.2 \%)$ & 9 & \\
\hline MIBC & $14(63.6 \%)$ & $8(36.4 \%)$ & 22 & \\
\hline NMIBC & $0(0 \%)$ & $1(100 \%)$ & 1 & \\
\hline Penile carcinoma & $2(100 \%)$ & $0(0 \%)$ & 2 & \\
\hline Testicular cancer & $5(100 \% \%)$ & 0 & 5 & \\
\hline \multicolumn{5}{|l|}{ ECOG Performance status (1 missing value) } \\
\hline Asymptomatic (0) & $36(58.1 \%)$ & $26(41.9 \%)$ & 62 & \multirow[t]{6}{*}{0.123} \\
\hline Symptomatic but completely ambulatory (1) & $46(65.7 \%)$ & $24(34.3 \%)$ & 70 & \\
\hline Symptomatic, $<50 \%$ in bed during the day (2) & $9(50.0 \%)$ & $9(50.0 \%)$ & 18 & \\
\hline Symptomatic, $>50 \%$ in bed, but not bedbound (3) & $8(100 \%)$ & $0(0 \%)$ & 8 & \\
\hline Bedbound (4) & $2(100 \%)$ & $0(0 \%)$ & 2 & \\
\hline Death (5) & $1(100 \%)$ & $0(0 \%)$ & 1 & \\
\hline
\end{tabular}

ECOG, Eastern Co-operative Oncology Group, UTUC, upper tract urothelial carcinoma, MIBC, muscle-invasive bladder cancer, NMIBC, nonmuscle-invasive bladder cancer

*Chisquare test in categorical variables, t-test in metric variables

Table 2 Therapy changes among substances

\begin{tabular}{llllll}
\hline Substance group & $N$ & Therapy interruption & Dose reduction $\geq 20 \%$ & $\begin{array}{l}\text { Therapy delay } \\
\geq 2 \text { weeks }\end{array}$ & Change of substance \\
\hline Androgen deprivation therapy & 29 & $1(3.4 \%)$ & $1(3.4 \%)$ & $5(17.2 \%)$ & $1(3.4 \%)$ \\
Chemotherapy & 41 & 0 & $1(2.45 \%)$ & $4(9.8 \%)$ & $1(2.4 \%)$ \\
IO treatment & 71 & 0 & 0 & $13(18.3 \%)$ & $0(0 \%)$ \\
Kinase inhibitors & 18 & 0 & 0 & $2(11.1 \%)$ & $1(5.6 \%)$ \\
Parp inhibitors & 2 & 0 & 0 & $0(0 \%)$ & $0(0 \%)$ \\
Total & 161 & $1(0.6 \%)$ & $2(1.2 \%)$ & $24(14.9 \%)$ & $3(1.9 \%)$ \\
$p$-value (Fisher's exact test) & & 0.304 & 0.322 & 0.746 & 0.179 \\
\hline
\end{tabular}

IO, immuno-oncologic; Parp, poly(ADP-ribose)-polymerase 
Table 3 Therapy changes among cancer entities

\begin{tabular}{|c|c|c|c|c|c|}
\hline Cancer entity & $N$ & Therapy interruption & $\begin{array}{l}\text { Dose reduction } \\
\geq 20 \%\end{array}$ & $\begin{array}{l}\text { Therapy delay } \\
\geq 2 \text { weeks }\end{array}$ & Change of substance \\
\hline Metastasized prostate cancer & 50 & $1(2 \%)$ & $1(2 \%)$ & $5(10 \%)$ & $2(4 \%)$ \\
\hline Testicular cancer & 5 & 0 & 0 & 0 & 0 \\
\hline Urothelial carcinoma & 32 & 0 & $1(3.1 \%)$ & $7(21.9 \%)$ & 0 \\
\hline Renal cell carcinoma & 73 & 0 & 0 & $12(16.4 \%)$ & $1(1.4 \%)$ \\
\hline Penile cancer & 2 & 0 & 0 & 0 & 0 \\
\hline Total & 162 & $1(0.6 \%)$ & $2(1.2 \%)$ & $24(14.8 \%)$ & $3(1.9 \%)$ \\
\hline$p$-value (Fisher's exact test, 2 -sided) & & 0.549 & 0.339 & 0.587 & 0.274 \\
\hline
\end{tabular}

cases $(30.2 \%)$, clinical follow-up had been cancelled and in $14 / 53$ cases $(26.4 \%)$ it was delayed. In $24 / 53$ cases $(45.3 \%$ ), blood tests had been cancelled, significantly more often in IO patients but with a small effect size $(21.1 \%, p=0.042$, $V=0.230$, Fig. 2). 20 of the 53 patients (37.7\%) experienced a delay in blood tests. The pandemic influenced the treatment of patients with renal cell carcinoma (RCC) $(12 / 73$, $16.4 \%$ ) and urothelial carcinoma (UC) (7/32, 21.9\%) more frequently than in those with prostate cancer $(5 / 50,10 \%)$ or testicular cancer ( $0 \%$, Fig. 3). Eleven of the 162 patients $(6.8 \%)$ died due to the progression of cancer.

\section{Discussion}

Chinese observations on SARS-CoV-2-infected cancer patients in three hospitals in Wuhan revealed that $53.6 \%$ of patients $(15 / 28)$ had severe events, with a mortality rate of $28.6 \%$ [10]. If the last antitumor treatment was within 14 days, it significantly increased the risk of developing severe events. Kuderer et al. [11] analyzed data from the USA, Canada and Spain from the COVID-19 and Cancer Consortium (CCC19) database between March 17 and April 16, 2020 and found a higher 30-day mortality in prostate cancer patients under systemic treatment.

This possible threat combined with other restraints in patient care due to the COVID-19 crisis led to delays and changes in therapy, as the literature shows. Froehling et al. [4] reported changes in radiologic diagnostics, systemic oncologic treatments and oncologic operations. Satish et al., showed a treatment delay or change in $43 \%$ of their breast cancer patients. Other groups revealed dose reductions or discontinuation of systemic cancer treatments [17]. Our data illustrate that $24(14.8 \%)$ patients in the total cohort experienced a delay in the systemic treatment of more than 2 weeks, of whom three patients (10\%) had a switch in their therapeutic agents. Most of these patients received IO treatments $(13 / 24,54.2 \%)$ or ADT $(5 / 24$, $20.8 \%, p=0.746)$. Recent data show an ongoing treatment effect of IO agents [18] after discontinuation, which could explain the highest rate of treatment delays in this group. Existing data indicate that survival rates for intermittent androgen deprivation (IAD) are similar to those for continuous ADT [19], which supports the possibility of treatment changes in this group during the COVID-19 crisis.

In line with several surveys and reports from Germany and other countries $[4,7,20]$, our data support a tendency towards delays in the follow-up care of UO patients, mainly during the first 6 weeks of COVID-19-related lockdown from March to mid-May 2020. Our study revealed that IO patients, in particular, experienced delays in follow-up care. Due to the fact that IO treatment agents are often less toxic than classical chemotherapeutic agents and that radiologic response varies among patients [21, 22], follow-up periods are defined less strictly. In contrast to other reports which could not show a relevant delay in laboratory diagnostics, our data illustrate that particularly blood tests had been delayed or cancelled in 43 cases (26.6\%), significantly more often in IO patients but with a small effect size $(21.1 \%, p=0.042, V=0.230)$.

The pandemic influenced the treatment of RCC (12/73, $16.4 \%)$ and UC $(7 / 32,21.9 \%)$ patients more frequently than those with prostate cancer $(5 / 50,10 \%)$ or testicular cancer $(0 \%)$, which might be due to the more invasive treatment in these groups. In general, patients with testicular cancer are often younger than other UO patients and therefore receive more aggressive treatments. This could explain why testicular patients did not experience any delays in therapy or follow-up. Still, it is alarming that two cancer types with a high risk for progression caused by delays [12] were affected the most.

Our data revealed that $11 / 162$ patients $(6.8 \%)$ died due to the progression of cancer. A recently published population-based study expects an increase in cancer mortality of $5-17 \%$ in England over the next 5 years due to a decrease in the presentation of suspected cancer cases and restricted diagnosis during COVID-19-caused lockdown [23]. To measure how and to what extent changes to therapy and follow-up have an impact on treatment and survival 

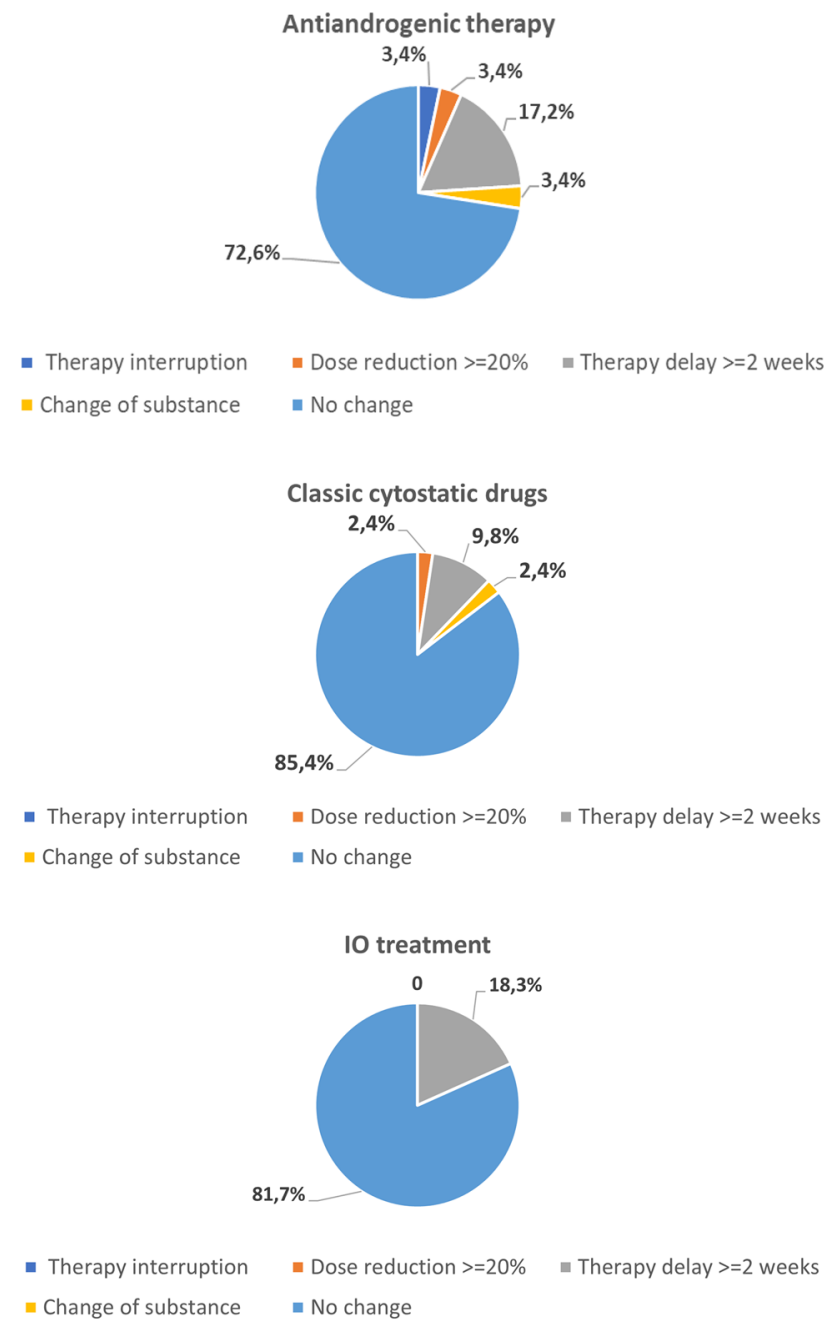

- Therapy interruption ․ Change of substance - No change

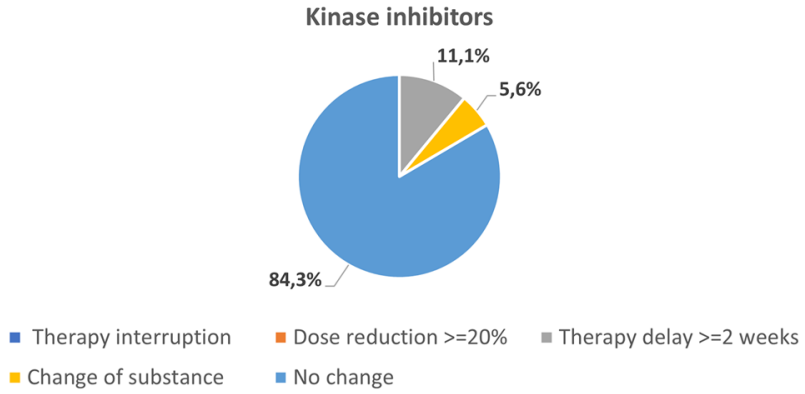

Fig. 1 Therapy changes by substance

outcome in UO patients, more long-term data analyses, e.g. from cancer registers, are needed over the years.

\section{Countermeasures and solutions}

In the following, we present some pragmatic measures that have been implemented in Germany and around the globe to cope with the health emergency related to COVID-19 and to counteract possible under-treatment of cancer patients, although the relative effectiveness of each intervention needs to be further analyzed in large observational studies. An Italian group around Panebianco suggested adapting guideline recommendations and integrating $\mathrm{mpMRI}$ in diagnostics for the management of bladder cancer as a risk-adapted strategy during the COVID-19 pandemic [24].

To avoid severe consequences of delayed in-house presentation as we have already reported for emergency units [9], it is necessary to keep in touch with patients during COVID19-caused lockdowns, especially UO patients who need systemic cancer therapies that cannot be delayed or which are associated with repetitive outpatient and inpatient hospital care. Prior to the COVID-19 crisis, our working group described the possibility of implementing telemedicine in urological care as well as the chances of digitalization for urology [25, 26]. Video consultations could help to avoid delays in UO follow-up and help the urologist to differentiate more easily the cases in which there is an urgent need for in-house consultations as well as those in which follow-up could be possibly delayed. Others have installed an online oncology platform for communicating with cancer patients [3]. Digitalization, especially the use of social media sources for disseminating medical information to a large audience making them valuable campaigning instruments [27] or by providing applications (apps) to optimize follow-up care [28], has the potential to optimize oncologic patient care and in this way it has enormous potential for the field of UO. Therefore, the German health care system needs structured campaigns to speed up digitalization in the near future.

Based on survey results, the German National Association of Urology (DGU e.V.) and the German Association of Uro-Oncologists (d-uo e.V.) [29] as well as the European association (EAU) [30] and other groups [31] have released suggestions of how to maintain oncologic and UO care in COVID-19-caused pandemics. For surgical urologic procedures, prioritization lists have been published and established [29]. Suggestions have been made to favor UO research, to limit recruitment of patients to studies with presumably "practice-changing" results and to replace on-site monitoring with remote monitoring $[3,32]$.

\section{Limitations}

However, our study is not devoid of limitations. We tried to avoid a possible selection bias by including university centers all over Germany, especially from Southern (BadenWuerttemberg and Bavaria) and Western Germany (North Rhine-Westphalia) which, taking into account the total number of infections and deaths, were much stronger affected by the crisis than the rest of the country [33]. Still, none of our patients died from COVID-19 and only one patient got infected by the virus, and he recovered fully afterwards. Our 
Table 4 Follow-up changes among substance groups

\begin{tabular}{|c|c|c|c|c|c|c|c|}
\hline Substance group & $N$ & Imaging cancelled & Imaging delayed & $\begin{array}{l}\text { Clinical } \\
\text { follow-up } \\
\text { cancelled }\end{array}$ & $\begin{array}{l}\text { Clinical } \\
\text { follow-up } \\
\text { delayed }\end{array}$ & $\begin{array}{l}\text { Laboratory } \\
\text { diagnostic } \\
\text { cancelled }\end{array}$ & $\begin{array}{l}\text { Laboratory } \\
\text { diagnostic } \\
\text { delayed }\end{array}$ \\
\hline Androgen deprivation therapy & 29 & $3(10.3 \%)$ & $1(3.4 \%)$ & $5(17.2 \%)$ & $3(10.3 \%)$ & $6(20.7 \%)$ & $2(6.9 \%)$ \\
\hline Conventional cytostatic drugs & 41 & $0(0 \%)$ & $5(12.2 \%)$ & $1(2.4 \%)$ & $4(9.8 \%)$ & $1(2.4 \%)$ & $8(19.5 \%)$ \\
\hline IO treatment & 71 & $1(1.4 \%)$ & $9(12.7 \%)$ & $8(11.3 \%)$ & $3(4.2 \%)$ & $15(21.1 \%)$ & $6(8.5 \%)$ \\
\hline Kinase inhibitors & 18 & $1(5.6 \%)$ & $2(11.1 \%)$ & $2(11.1 \%)$ & $4(22.2 \%)$ & $2(11.1 \%)$ & $4(22.2 \%)$ \\
\hline Parp inhibitors & 2 & $0(0 \%)$ & $0(0 \%)$ & $0(0 \%)$ & $0(0 \%)$ & $0(0 \%)$ & $0(0 \%)$ \\
\hline Total & 161 & $5(3.1 \%)$ & $17(10.6 \%)$ & $16(9.9 \%)$ & $14(8.7 \%)$ & $24(14.9 \%)$ & $20(12.4 \%)$ \\
\hline$p$-value (Fisher's exact test) & & 0.102 & 0.672 & 0.256 & 0.157 & 0.042 & 0.218 \\
\hline Cramér's $V$ & & 0.215 & 0.118 & 0.171 & 0.198 & 0.230 & 0.187 \\
\hline
\end{tabular}

IO, immuno-oncologic; Parp, poly(ADP-ribose)-polymerase

Table 5 Follow-up changes among cancer entities

\begin{tabular}{|c|c|c|c|c|c|c|c|}
\hline Cancer entity & $N$ & Imaging cancelled & Imaging delayed & $\begin{array}{l}\text { Clinical } \\
\text { follow-up } \\
\text { cancelled }\end{array}$ & $\begin{array}{l}\text { Clinical } \\
\text { follow-up } \\
\text { delayed }\end{array}$ & $\begin{array}{l}\text { Laboratory } \\
\text { diagnostic } \\
\text { cancelled }\end{array}$ & $\begin{array}{l}\text { Laboratory } \\
\text { diagnostic } \\
\text { delayed }\end{array}$ \\
\hline Metastasized prostate cancer & 50 & $3(6 \%)$ & $2(4 \%)$ & $5(10 \%)$ & $5(10 \%)$ & $8(16 \%)$ & $3(6 \%)$ \\
\hline Testicular cancer & 5 & 0 & 0 & 0 & 0 & 0 & 0 \\
\hline Urothelial carcinoma & 32 & 0 & $5(15.6 \%)$ & $4(12.5 \%)$ & $1(3.1 \%)$ & $6(18.8 \%)$ & $2(6.3 \%)$ \\
\hline Renal cell carcinoma & 73 & $2(2.7 \%)$ & $10(13.7 \%)$ & $7(9.6 \%)$ & $9(12.3 \%)$ & $11(15.1 \%)$ & $15(20.5 \%)$ \\
\hline Penile cancer & 2 & 0 & 0 & 0 & 0 & 0 & 0 \\
\hline Total & 162 & $5(3.1 \%)$ & $17(10.5 \%)$ & $16(9.9 \%)$ & $15(9.3 \%)$ & $25(15.4 \%)$ & $20(12.3 \%)$ \\
\hline$p$-value (Fisher exact test, 2 -sided) & & 0.544 & 0.322 & 0.946 & 0.602 & 0.930 & 0.107 \\
\hline
\end{tabular}

data suggest that the shielding of uro-oncological patients at German university hospitals could have been effective during the first wave of COVID-19. Furthermore, the suggestions released by the national (March 2020) and European (May 2020) associations described earlier could have had a positive impact.

We initially started our analysis in October 2019 to examine not only the first wave of COVID-19 but also the influence of seasonal flu on uro-oncological patients under ongoing system therapy. Since none of our patients contracted the flu and the flu wave in 2019 was relatively mild, we could not determine any effects/deviations and discarded this analysis. All reported changes regarding aftercare and therapy fell during the period of the first COVID-19 wave and the first COVID-related lockdown in Germany from February 2020 to June 2020 and are to be related to this.

Our study does not claim to stand for UO care in the whole country but it demonstrates the impact of concentrating the medical resources of German university hospitals to fight the COVID-19 crisis on the medical care of
UO patients. Apart from prioritization, capacity shortages of medical employees, who had to be in quarantine which resulted in shrinking capacity for UO patients on wards and in outpatient departments, had an additional impact on the medical care of UO patients during the first months of the crisis.

\section{Conclusions}

The COVID-19 crisis had an impact on follow-up care in one-third of cases and on systemic treatment in one-fifth. There was a tendency towards delays in IO and ADT treatments in particular. Data prove that the crisis has had an impact on the medical care of UO patients but so far yield no statistically measurable prognostic or survival impact. Long-term follow-up data are needed and will be delivered for further evaluations.

Acknowledgements No funding or sponsorship was received for this study or publication of this article. All authors had full access to all the data in this study and take complete responsibility for the integrity of 
Fig. 2 Follow-up changes by substance

\section{Follow-up changes by substance}

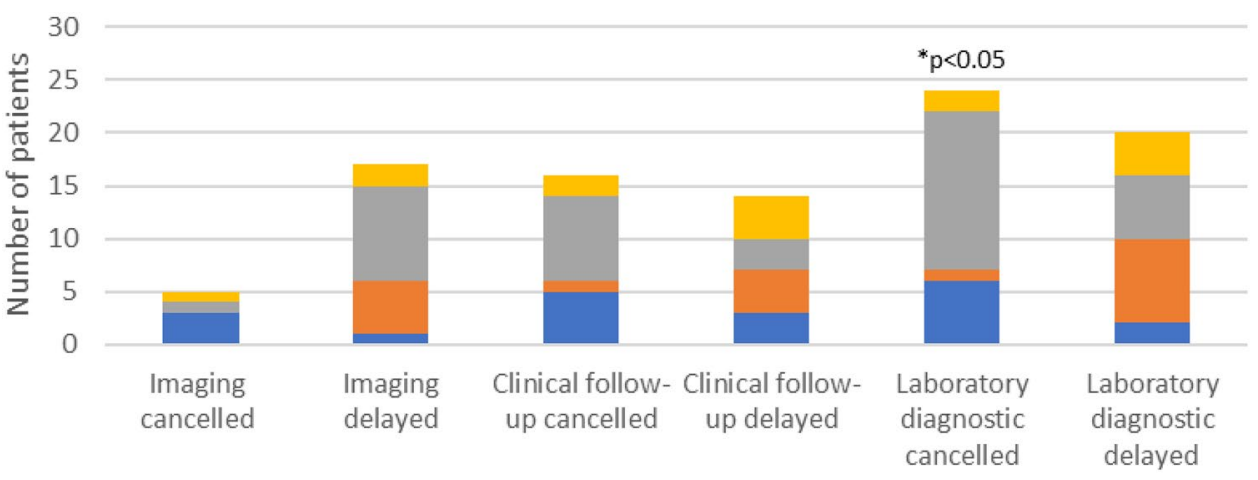

antiandrogenic therapy $\quad$ Classic cytostatic drugs $\quad$ IO treatment $\quad$ Kinase inhibitors

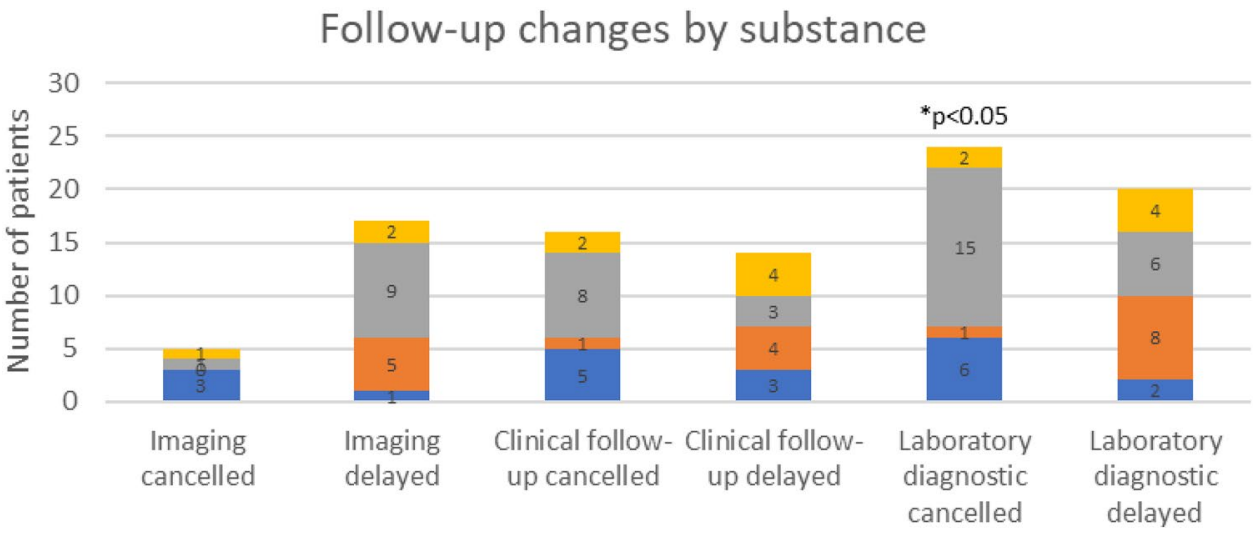

the data and accuracy of the data analysis. All named authors meet the International Committee of Medical Journal Editors (ICMJE) criteria for authorship for this article, take responsibility for the integrity of the work as a whole, and have given their approval for this version to be published. The figures are original and have been produced by the authors.

Author contributions SJP (first author): project/protocol development, data collection, data management, data analysis, manuscript writing and editing. MAS (senior author): project/protocol development, data management, data analysis, manuscript editing. SM: data management, data analysis. SA: data collection, data management. HMC: manuscript editing. OT: manuscript editing. KMW: project/protocol development, manuscript editing. OIA: data collection, manuscript editing. SMJ: data collection, manuscript editing. BM: data collection, manuscript editing. DC: data collection, manuscript editing. GV: data collection, manuscript editing. HB: data collection, manuscript editing. WM: data collection, manuscript editing. $\mathrm{KH}$ : data collection, manuscript editing. KJC: data collection, manuscript editing. GMT: data collection, manuscript editing. GC: data collection, manuscript editing. KA: project/protocol development, data management, data analysis, manuscript editing.
Funding Open Access funding enabled and organized by Projekt DEAL. No funding or sponsorship was received for this study or publication of this article.

Data availability Access to associated data will be granted on request to the main or senior author.

\section{Declarations}

Conflicts of interest The authors declare that they have no conflicts of interest.

Ethics approval This article does not contain any studies with human participants or animals performed by any of the authors. Respective ethics approval was obtained from the Ethics Committee of the University of Luebeck (no. 20-156).

Open Access This article is licensed under a Creative Commons Attribution 4.0 International License, which permits use, sharing, adaptation, distribution and reproduction in any medium or format, as long as you give appropriate credit to the original author(s) and the source, provide a link to the Creative Commons licence, and indicate if changes were made. The images or other third party material in this article are 


\section{Metastasized prostate cancer}
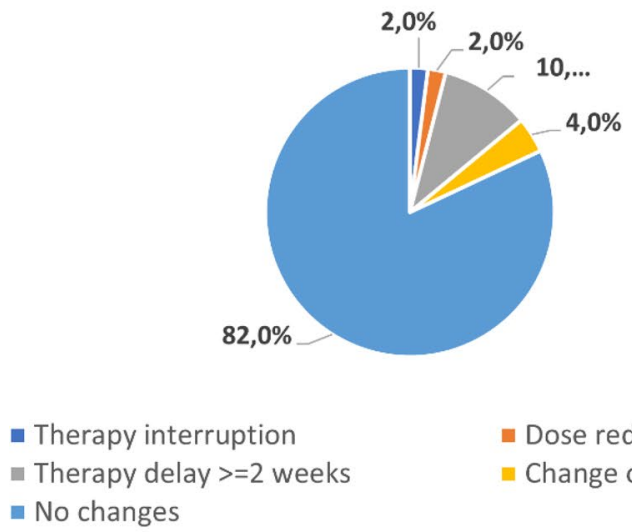

\section{Renal cell carcinoma}

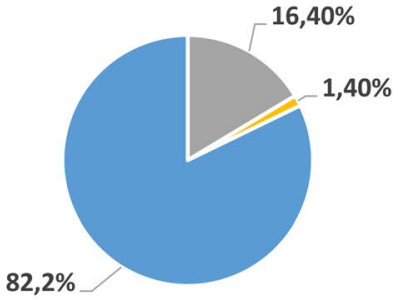

$$
\begin{aligned}
& \text { - Therapy interruption } \quad \text { Dose reduction }>=20 \% \\
& \text { - Therapy delay }>=2 \text { weeks } \| \text { Change of substance } \\
& \text { - No changes }
\end{aligned}
$$

\section{Urothelial carcinoma (NMIBC, MIBC, UTUC)}

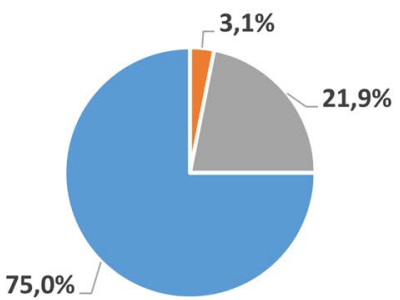

$$
\begin{aligned}
& \text { - Therapy interruption } \\
& \text { - Therapy delay >=2 weeks } \\
& \text { - No changes }
\end{aligned}
$$$$
\text { - Dose reduction }>=20 \%
$$$$
\text { - Change of substance }
$$

Fig. 3 Therapy changes by entity

included in the article's Creative Commons licence, unless indicated otherwise in a credit line to the material. If material is not included in the article's Creative Commons licence and your intended use is not permitted by statutory regulation or exceeds the permitted use, you will need to obtain permission directly from the copyright holder. To view a copy of this licence, visit http://creativecommons.org/licenses/by/4.0/.

\section{References}

1. WHO Coronavirus (COVID-19) Dashboard [Internet] (2021) https://covid19.who.int. Accessed 10 Mar 2021

2. Mortality Analyses [Internet] (2021) Johns Hopkins Coronavirus Resource Center. https://coronavirus.jhu.edu/data/mortality. Accessed 10 Mar 2021

3. Weisel KC, Morgner-Miehlke A, Petersen C, Fiedler W, Block A, Schafhausen $P$ et al (2020) Implications of SARS-CoV-2 infection and COVID-19 crisis on clinical cancer care: report of the university cancer center Hamburg. Oncol Res Treat 43(6):307-313

4. Froehling S, Arndt V. Versorgung von Krebspatienten: CoronaEffekt in der Onkologie. Deutsches Ärzteblatt. 2020;75.

5. Kwon YS, Tabakin AL, Patel HV, Backstrand JR, Jang TL, Kim IY et al (2020) Adapting urology residency training in the COVID-19 era. Urology 141:15-19

6. Spagnolo J, Gautier L, Seppey M, Dsouza NA (2020) Re-thinking global and public health projects during the COVID-19 pandemic context: considerations and recommendations for earlyand not-so-early-career researchers. Soc Sci Humanities Open. 2(1): 100075

7. Teoh JY-C, Ong WLK, Gonzalez-Padilla D, Castellani D, Dubin JM, Esperto F et al (2020) A global survey on the impact of COVID-19 on urological services. Eur Urol 78(2):265-275

8. Søreide K, Hallet J, Matthews JB, Schnitzbauer AA, Line PD, Lai PBS et al (2020) Immediate and long-term impact of the COVID-19 pandemic on delivery of surgical services. Br J Surg 107(10):1250-1261

9. Borgmann H, Struck JP, Mattigk A, Wenzel M, Pilatz A, Kranz $\mathrm{J}$ et al (2021) Increased severe adverse outcomes and decreased emergency room visits for pyelonephritis: first report of collateral damage during COVID-19 pandemic in urology. Urol Int 105(3-4):199-205

10. Zhang L, Zhu F, Xie L, Wang C, Wang J, Chen R et al (2020) Clinical characteristics of COVID-19-infected cancer patients: a retrospective case study in three hospitals within Wuhan. China Ann Oncol 31(7):894-901

11. Kuderer NM, Choueiri TK, Shah DP, Shyr Y, Rubinstein SM, Rivera DR et al (2020) Clinical impact of COVID-19 on patients with cancer (CCC19): a cohort study. Lancet 395(10241):1907-1918

12. Kutikov A, Weinberg DS, Edelman MJ, Horwitz EM, Uzzo RG, Fisher RI (2020) A war on two fronts: cancer care in the time of COVID-19. Ann Intern Med. https://www.ncbi.nlm.nih.gov/pmc/ articles/PMC7133056/. Accessed 10 Mar 2021

13. Martinelli F, Garbi A (2020) Change in practice in gynecologic oncology during the COVID-19 pandemic: a social media survey. Int J Gynecol Cancer 30(8):1101-1107

14. Wissenschaftliches Institut der AOK (WIdO) (2021) Monitor: Vorerkrankungen mit erhöhtem Risiko für schwere Covid19-Verläufe [Internet]. https://www.wido.de/fileadmin/Dateien/ Dokumente/News/wido_dat_correct_paper_covid-19_2020.pdf. Accessed 7 Oct 2021

15. Cohen J (1988) Statistical power analysis for the behavioral sciences. Erlbaum Associates, Hillsdale, p 567

16. Ellis PD (2010) The essential guide to effect sizes: statistical power, meta-analysis, and the interpretation of research results [Internet]. Cambridge University Press, Cambridge. https://www. core/books/essential-guide-to-effect-sizes/72C26CA99366A19 CAC4EF5B16AE3297F. Accessed 8 Mar 2020

17. Richards M, Anderson M, Carter P, Ebert BL, Mossialos E (2020) The impact of the COVID-19 pandemic on cancer care. Nat Cancer 20:1-3 
18. Robert C, Ribas A, Hamid O, Daud A, Wolchok JD, Joshua AM et al (2018) Durable complete response after discontinuation of pembrolizumab in patients with metastatic melanoma. J Clin Oncol 36(17):1668-1674

19. Sciarra A, Abrahamsson PA, Brausi M, Galsky M, Mottet N, Sartor $\mathrm{O}$ et al (2013) Intermittent androgen-deprivation therapy in prostate cancer: a critical review focused on phase 3 trials. Eur Urol 64(5):722-730

20. Efthimiou I (2020) Urological services in the era of COVID-19. Urol J 17(5):534-535

21. Rimola J, Da Fonseca LG, Sapena V, Perelló C, Guerrero A, Simó MT et al (2021) Radiological response to nivolumab in patients with hepatocellular carcinoma: A multicenter analysis of real-life practice. Eur J Radiol 135:109484

22. Wang GX, Kurra V, Gainor JF, Sullivan RJ, Flaherty KT, Lee SI et al (2017) Immune checkpoint inhibitor cancer therapy: spectrum of imaging findings. Radiographics 37(7):2132-2144

23. Maringe C, Spicer J, Morris M, Purushotham A, Nolte E, Sullivan $\mathrm{R}$ et al (2020) The impact of the COVID-19 pandemic on cancer deaths due to delays in diagnosis in England, UK: a national, population-based, modelling study. Lancet Oncol 21(8):1023-1034

24. Panebianco V, Del Giudice F, Leonardo C, Sciarra A, Catalano C, Catto JWF (2020) VI-RADS scoring criteria for alternative riskadapted strategies in the management of bladder cancer during the COVID-19 pandemic. Eur Urol 78(1):e18-20

25. Struck JP, Wenzel M, Heidenreich A, Merseburger A, Salem J (2018) Implementation of telemedicine in daily care of urological patients. Aktuelle Urol 49(6):509-514

26. Salem J, Struck JP (2019) The importance of digitalisation in urology. Aktuelle Urol 50(4):386-391

27. Sosnowski R, Lemiński A, van Gurp M (2016) Social media-the growing role in urology. Cent Eur J Urol 69(3):299-300
28. Jensen BT, Lauridsen SV, Jensen JB (2020) Optimal delivery of follow-up care after radical cystectomy for bladder cancer. Res Rep Urol 14(12):471-486

29. Johannsen M, Klier J, König F, Eichenauer R, Schönfelder R, Schröder J et al (2020) Management von Krebspatienten in Zeiten der Coronavirus-Pandemie, Deutsche Gesellschaft für Urologie, p 2

30. Amparore D, Campi R, Checcucci E, Sessa F, Pecoraro A, Minervini A et al (2020) Forecasting the future of urology practice: a comprehensive review of the recommendations by International and European associations on priority procedures during the COVID-19 pandemic. Eur Urol Focus 6(5):1032-1048

31. Hanna TP, Evans GA, Booth CM (2020) Cancer, COVID-19 and the precautionary principle: prioritizing treatment during a global pandemic. Nat Rev Clin Oncol 17(5):268-270

32. FRANCISCO EM (2020) Guidance to sponsors on how manage clinical trials during the COVID-19 pandemic [Internet]. European Medicines Agency. https://www.ema.europa.eu/en/news/ guidance-sponsors-how-manage-clinical-trials-during-covid-19pandemic. Accessed 7 Apr 2021

33. RKI-Coronavirus SARS-CoV-2-COVID-19 (2021) Fallzahlen in Deutschland und weltweit [Internet]. https://www.rki.de/DE/ Content/InfAZ/N/Neuartiges_Coronavirus/Fallzahlen.html/. Accessed 14 Oct 2021

Publisher's Note Springer Nature remains neutral with regard to jurisdictional claims in published maps and institutional affiliations.

\section{Authors and Affiliations}

\section{Julian P. Struck ${ }^{1}$ (1) - Maike Schnoor ${ }^{2} \cdot$ Andrea Schulze $^{1} \cdot$ Marie C. Hupe ${ }^{1} \cdot$ Tomasz Ozimek $^{1} \cdot$ Immanuel A. Oppolzer $^{3}$. Marco J. Schnabel ${ }^{3}$. Maximilian Burger ${ }^{3}$. Christopher Darr ${ }^{4}$. Viktor Gruenwald ${ }^{4}$. Boris Hadaschik ${ }^{4}$.

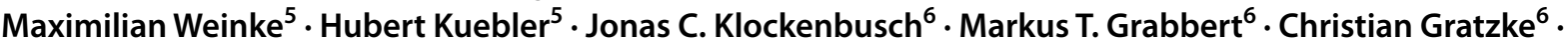 Mario W. Kramer ${ }^{1} \cdot$ Alexander Katalinic $^{2}$. Axel S. Merseburger ${ }^{1}$}

\author{
Maike Schnoor \\ Maike.Schnoor@uksh.de \\ Andrea Schulze \\ Andrea.Schulze@uksh.de; andrea.saubke@uk-essen.de \\ Marie C. Hupe \\ mariechristine.hupe@uksh.de \\ Tomasz Ozimek \\ Tomasz.Ozimek@uksh.de \\ Immanuel A. Oppolzer \\ ioppolzer@caritasstjosef.de \\ Marco J. Schnabel \\ marco.schnabel@ukr.de \\ Maximilian Burger \\ maximilian.burger@ukr.de \\ Christopher Darr \\ Christopher.Darr@uk-essen.de \\ Viktor Gruenwald \\ viktor.gruenwald@uk-essen.de
}

Boris Hadaschik

andrea.saubke@uk-essen.de

Maximilian Weinke

Weinke_M2@ukw.de

Hubert Kuebler

riedl_m@ukw.de

Jonas C. Klockenbusch

jonas.caspar.klockenbusch@uniklinik-freiburg.de

Markus T. Grabbert

markus.grabbert@uniklinik-freiburg.de

Christian Gratzke

Christian.gratzke@uniklinik-freiburg.de

Mario W. Kramer

Mario.kramer@uksh.de

Alexander Katalinic

Alexander.Katalinic@uksh.de

Axel S. Merseburger

axel.merseburger@uksh.de 
1 Department of Urology, University Hospital SchleswigHolstein, Campus Luebeck, Ratzeburger Allee 160, 23538 Luebeck, Germany

2 Department of Social Medicine and Epidemiology and Department of Cancer Epidemiology, University of Luebeck, Ratzeburger Allee 160, 23562 Luebeck, Germany

3 Department of Urology, University Hospital of Regensburg, Landshuter Straße 65, 93053 Regensburg, Germany
4 Department of Urology, Pediatric Urology and Uro-Oncology, University Hospital of Essen, Hufelandstraße 55, 45147 Essen, Germany

5 Department of Urology and Pediatric Urology, University Hospital of Wuerzburg, Oberduerrbacher Straße 6, 97080 Wuerzburg, Germany

6 Department of Urology, University Hospital of Freiburg, Hugstetterstraße 55, 79106 Freiburg im Breisgau, Germany 